\title{
Eskola-inplikazioa: kontzeptua, neurketa, aldakortasuna eta testuinguruaren aldagaiak nahiz aldagai psikologikoak
}

\author{
Estibaliz Ramos Díaz \\ Arantza Fernández Zabala \\ Bilakaeraren eta Hezkuntzaren Psikologia \\ Gasteizko Irakasleen Unibertsitate Eskola \\ Euskal Herriko Unibertsitatea (UPV/EHU) \\ Ana Zuazagoitia Rey-Baltar \\ Musika, Plastika eta Gorputz Hezkuntzaren Didaktika \\ Gasteizko Irakasleen Unibertsitate Eskola \\ Euskal Herriko Unibertsitatea (UPV/EHU) \\ Arantzazu Rodríguez Fernández \\ Bilakaeraren eta Hezkuntzaren Psikologia \\ Gasteizko Irakasleen Unibertsitate Eskola \\ Euskal Herriko Unibertsitatea (UPV/EHU) \\ Iker Ros Martínez de la Hidalga \\ Musika, Plastika eta Gorputz Hezkuntzaren Didaktika \\ Gasteizko Irakasleen Unibertsitate Eskola \\ Euskal Herriko Unibertsitatea (UPV/EHU)
}

DOI: $10.1387 /$ tantak.15561

GAKO-HITZAK: eskola-inplikazioa, berrikuste teorikoa, testuinguruaren aldagaiak, aldagai psikologikoak, bigarren hezkuntza.

\section{SARRERA}

Garai batean, hezkuntzaren psikologiaren alorrean egindako ikerketak gabezietan ardazten ziren batez ere, baina, azken urteotan, ikasleen indarguneak eta ezaugarri positiboak aztertzea xede duen ikerketa nagusitu da (Kristjánsson, 2012). Ezaugarri horien artean eskola-inplikazioa edo school engagement delakoa nabarmentzen da, garapen psikosozialerako eta arrakasta akademikoa erdiesteko elementu erabakigarritzat jotzen den 
kontzeptu zientifikoa (Motti-Stefadini eta Masten, 2013; Ros, Goikoetxea, Gairín, eta Lekue, 2012), eta errendimendu baxuaren, inplikazio faltaren nahiz eskola-uzte tasa altuen aurkako irtenbidea izan daitekeena (ZimmerGembeck, Chipuer, Hanisch, Creed, eta McGregor, 2006).

Lan honetan eskola-inplikazioaren inguruko kontzeptualizazioaren, ebaluazioaren eta aldakortasunaren berrikuspen teorikoa egiten da. Halaber, ikasleen testuinguruaren zenbait aldagai (familiaren, berdinen zein irakasleen babesa) eta hainbat aldagai psikologiko (autokontzeptua eta erresilientzia) aztertzen dira psikologia positiboaren eta ekologiaren ikuspegitik, eskola-inplikazioarekin lotura duten alderdiak direlakoan.

\section{ESKOLA-INPLIKAZIOAREN KONTZEPTUALIZAZIOA}

Eskola-inplikazioa 1980ko hamarkadan kontzeptualizatu zen lehen aldiz, eta eskola-uztea ulertu nahiz Bigarren Hezkuntzako ikasketak arrakastaz amaitzea sustatzea helburu duen lehen eredu teorikotzat jotzen da (Christenson, Reschly, eta Wylie, 2012; Finn eta Zimmer, 2012). Nahiz eta egun ikaslea ikastetxean inplikatzeak duen garrantzia nabarmentzen duten lan ugari aurki daitezkeen, adituak ez dira ados jartzen kontzeptua zehazteko orduan eta eztabaidagaia da oraindik ere ikerlarien artean (Appleton, Christenson, eta Furlong, 2008; Fredricks, Blumenfeld eta Paris, 2004; Furlong et al., 2003; Perdue, Manzesek, eta Estell, 2009). Hala eta guztiz ere, eskola-inplikazioa, eskuarki, honela definitu izan da: ikaslea eskolan zein neurritan inplikatzen den eta ikasteko zer nolako motibazioa duen ( $\mathrm{Si}$ mons-Morton eta Chen, 2009).

Eskola-inplikazioari buruzko lehen ikerketek ikasleen inplikazioa bultzatu edo oztopatzen duten eta ikastetxeen esku dauden alderdiak nabarmendu zituzten, eskola-testuingurua aipatutako aldagaiaren bitarteko eragilea zela argudiatzen baitzuten (Newmann, 1981; Wehlage, Rutter, Smith, Lesko, eta Fernandez, 1989). Geroago, pertsonaren baitako dinamiken inguruan ardaztu zen ikerkuntza; izan ere, aintzat hartu zen gizaki orok oinarrizko beharrak dituela: gaitasunen garapena, autonomia eta sozializazioa (Connell eta Wellborn, 1991). Ikuspegi horren arabera, barne-prozesuen emaitza inplikazioa (engagement) edo inplikazio falta (disengagement) izan daiteke, eta inplikazioak edota inplikazio faltak, era berean, jokabide soziala baldintzatzen du, eta horrek, azken buruan, eragina du doitzean (Skinner, Kinderman, Connell, eta Wellborn, 2009). Hirugarren ikusmolde bat ere bada, aurreko bien ezaugarriak bateratzen dituena, alegia, testuinguruari dagozkionak nahiz pertsonen baitakoak. Finn-en (1989) parte-hartze eta identifikazio ereduak, zehazki, portaerak eta afektuak elkar eragiten dutela azaltzen du, eta elkarreragin horrek, era berean, eragina duela arrakasta akademikoan; izan ere, ikerlariaren arabera, parte-hartze goiztiarrak, denboraren poderioz, ikastetxearekin identifikatzea dakar, eta ondoren, 
parte-hartze jarraitua. Horiek horrela, eskola-inplikazio kontzeptu zientifikoa honakoek osatzen dute: osagai konduktual batek, eskolan parte-hartzea barne hartzen duena, eta osagai psikologiko edo emozional batek, ikastetxearenganako identifikazio-sentimenduarekin lotuta dagoena. Finn-en (1989) dimentsio biko proposamenaren ostean, eskola-inplikazio kontzeptua berrikusi eta eguneratu egin zen (Appleton et al., 2008; Fredricks et al., 2004), eta osagai kognitibo bat (inplikazio intelektuala edo akademikoa) erantsi zitzaion.

Egun, zientzialari gehienak bat datoz, eta kontzeptuak alderdi asko barne hartzen dituela onartzen da (Lewis, Huebner, Malone, eta Valois, 2011; Simons-Morton eta Chen, 2009; Wang, Willet, eta Eccles 2011), eta bi eta lau osagai artean izan ditzakeela baieztatzen da (Christenson et al., 2012). Eta eskola-inplikazioa osatzen duten dimentsioak zenbat eta zein diren zehazteke dagoen arren (Li eta Lerner, 2013), ikertzaileen arteko adostasuna gero eta handiagoa da (Appleton, 2012; Christenson et al., 2012; Fredricks et al., 2004; Furlong eta Christenson, 2008; Glanville eta Wildhagen, 2007; Jimerson, Campos, eta Grief, 2003), eta gehienen ustez, ikaslearen inplikazioa meta-kontzeptua da eta elkarrekiko lotura duten hiru dimentsiok osatzen dute: kognitiboak, emozionalak eta konduktualak.

Dimentsio konduktualak kontuan hartzen du ikasleak eskolako ekintzetan zer nolako parte-hartzea duen. Alderdi hori aztertu duten adituen arabera, eskolan ekintza nahiz jardunbide positiboak gauzatzean datza, esate baterako, ikaskuntza-eginkizunak gauzatzean (Reschly eta Christenson, 2006), eskoletara joatean eta arreta jartzean (Voelkl, 2012), eskolako lanak egiteko ahaleginean eta arrakasta akademikoan (Wang eta Holcombe, 2010), eta jokabide suntsitzailerik ez izatean nahiz eskolako arauak errespetatzean (Appleton, 2012; Fredricks et al., 2004; Burden eta Burdett, 2005). Dimentsio emozionalak edo psikologikoak, aldiz, ikasleak eskolarekin duen harremana edota eskolarenganako identifikazio-sentimendua du bereizgarri (Appleton,Christenson, Kim, eta Reschly, 2006; Finn, 1989; Voelk, 2012), eta eskolak, ikaskideek nahiz irakasleek ikaslearengan eragiten dituzten erreakzio emozionalak (Glanville eta Widhagen, 2007; Marks, 2000; Yazzie-Mintz, 2007). Halaber, ikasleak eskolarekin duen harremana aztertzen du: ikaslea ikastetxearen parte sentitzen den, ikaskideekiko harremanik duen, pozik dagoen eta ikastetxeko kide edo partaide sentitzen den (Furrer eta Skinner, 2003; Ros, 2014). Amaitzeko, dimentsio kognitiboak ikaslea ikaskuntzan zein neurritan ahalegintzen den aztertzen du; alegia, arazoak konpontzeko orduan ikasleak malgutasunik duen, zer nolako ahalegina egiten duen ikasteko eta zein auto-erregulazio estrategia baliatzen duen (Fredricks et al., 2004).

Laburbilduz, eskola-inplikazioak barne hartzen ditu ikasleek eskolatestuinguruan bizi dituzten esperientzien inguruan adierazten dituzten sentimenduak, pentsamenduak eta jarrerak. Horrenbestez, adituak bat datozen arren eskola-inplikazioak hainbat osagai dituela baieztatzean, ikerketen ar- 
teko aldeak aurkituko ditugu osagaion kopuruari eta kontzeptualizazioari dagokionez (Veiga, Burden, Appleton, Céu, eta Galvao, 2014).

Inplikazioaren eta motibazioaren arteko lotura ere eztabaidagai izan da ikerlarien artean (Appleton et al., 2006, 2008). Motibazioari buruzko teorien arabera (Connell eta Wellborn, 1991; Maslow, Frager, eta Cox, 1970; McClelland, 1985), motibazioaren sorburua ezkutuan dauden behar psikologikoak asetzeko beharra da, besteak beste, autonomia (Skinner et al., 2009) edo gaitasunen garapena (Furlong eta Christenson, 2008). Eskolainplikazioari buruzko teoriek (Finn, 1981; Voelkl, 1997), ordea, inplikazioaren garapena ikaslearen eta jardueraren arteko lotura eragiten duten eta progresiboki barneratzen diren jokabide-ereduen araberakoa dela baieztatzen dute (Rusell, Ainley, eta Frydenberg, 2005). Esaterako, Reeve-ren arabera (2012), motibazioa prozesu pribatua, beha ezina, psikologikoa, neuronala eta biologikoa da, publikoki beha daitekeen jokabidearen aurretikoa; hots, inplikazioaren aurrekaria. Hori dela eta, Reevek motibazioak eta inplikazioak elkarri eragiten diotela nabarmentzen du, eta horregatik jotzen dute inplikazioa motibazio-prozesuen emaitzatzat motibazioa ardatz duten ikerketek, eta motibazioa inplikazio-iturritzat inplikazioari buruzko azterketek. Horrenbestez, badirudi motibazioa kausa pribatua eta subjektiboa dela, eta inplikazioa, ostera, objektiboki behagarria den ondorioa.

\section{ESKOLA-INPLIKAZIOAREN NEURKETA}

Eskola-inplikazioaren ebaluazioak ikasleek beren buruaz emandako informazioa baliatu izan du nagusiki neurketak egiteko. Alabaina, ikasleei eskatutako informazioa ez da beti bera; izan ere, lehenago adierazi bezala, eskola-inplikazioa alderdi ugari dituen kontzeptua da, eta kontzeptua definitzean zehazten diren alderdien arabera, ikasleei eskatzen zaien informazioa bat edo beste izango da (Fredricks eta McColskey, 2012).

Ikasleek beren buruaz informazioa eman dezaten, eskola-inplikazioa islatzen duten hainbat item ematen zaizkie, beren egoera egokien deskribatzen duena aukera dezaten. Baina, zergatik jaso ikasleek beren buruaz ematen duten informazioa? Ikastetxeek jokabideari buruzko adierazleen inguruko datu objektiboak jaso ohi dituzte (ikasleek amaitzen dituzten egitekoen kopurua edota bertaratzea), baina ikasleek beren buruaz ematen duten informazio ebaluazio-neurgailutzat erabiltzearen aldeko argudioetako bat izaten da ikasleen hautemate subjektiboen inguruko informazioa jasotzea ahalbidetzen duela (Appleton et al., 2006).

Ikasleek beren buruaz ematen duten informazioa erabili duten ikerketen artean, ingelesez egindako honako hauek nabarmendu beharra dago, besteak beste: Yazzie-Mintz-en (2007) High School Survey of Student Engagement (HSSSE) eta Fredriks, Blumenfeld, Friedel eta Paris-en (2005) 
School Engagement Measure (SEM). Izan ere, hiru alderditan (inplikazio konduktuala, emozionala eta kognitiboa) oinarritutako egitura dute:

- Yazzie-Mintz-en (2007) High School Survey of Student Engagement (HSSSE) galdetegiak 121 item ditu honako eskaletan antolatuak: inplikazio kognitibo/intelektual/akademikoa (65 item), inplikazio soziala, konduktuala eta partizipatiboa (17 item) eta inplikazio emozionala (39 item). Jatorrizko laginean Ipar Ameriketako Bigarren Hezkuntzako 4 ikastetxetako 7.200 ikaslek hartu zuten parte. Galdetegia herrialdeko landa-eremuko, hiri inguruko eta hirietako ikastetxeetan ikasten ari ziren profil etniko eta sozioekonomiko anitzetako 200.000 ikasleri banatu zaie.

- Fredericks-en eta bere kideen (2005) School Engagement Measure (SEM) delakoak 19 item ditu; horietatik 17 modu positiboan idatziak eta 2 modu negatiboan, eta erantzunak emateko bost graduko Likert eskala $(1$ = inoiz ez, 5 = beti) erabili da. Jatorrizko bertsioko elementuen analisi faktoriala eginez gero, hiru eskala daude: inplikazio konduktuala ebaluatzen duena (5 item), inplikazio emozionala neurtzen duena (6 item) eta inplikazio kognitiboari buruzko ondorioak ateratzeko baliagarri dena (8 item). Jatorrizko laginean Bigarren Hezkuntzako auzo-ikastetxeetako maila sozioekonomiko baxuko 641 ikasle afroamerikar eta latindarren erantzunak aztertu ziren. Ondoren beste maila sozioekonomiko batzuetako ikasleekin ere erabili izan da. Egileen arabera, egindako hainbat azterketek ingelesezko bertsioaren baliotasuna baieztatzen dute (Blumenfeld et al., 2005; Fredricks et al., 2005; Fredricks eta McColskey, 2012).

Eskola-inplikazioa neurtzeko ezaugarri psikometriko egokiak dituzten neurketa-tresna kopurua nabarmen handitu denez gero, ikasleen inplikazioaren boterea eta balioa indartu egin dira, eta aldagai baliagarritzat jotzen dira ikastetxeetako erabakitze-prozesuen inguruan datu enpirikoetan oinarritutako ikerketak egiteko (Betts, Appleton, Reschly, Christenson, eta Huebner, 2010; Fredricks eta McColskey, 2012). Haatik, Espainiar estatuan, gai honen inguruko ikerketak urriak dira (Ros, 2009; González, 2010; Ros et al., 2012), eta hori dela eta, hiru dimentsioko ikuspegian oinarrituko gaztelaniazko oso neurketa-tresna gutxi daude nerabeen egoera aztertzeko.

\section{ESKOLA-INPLIKAZIOAREN ALDAKORTASUNA, SEXUAREN ETA IKASKETA-MAILAREN ARABERA}

Atal honetan, hainbat ezaugarri sozial eta pertsonalen (sexua eta ikasketa-maila) arabera eskola-inplikazioa nola aldatzen den aztertu duten ikerketen laburpena egiten da. 


\subsection{Eskola-inplikazioa eta sexua}

Oso lan gutxik aztertu dute sexu ezberdintasunak eskola-inplikazioan duen eragina; Lam, Wong, Yang eta Liu-k (2012) gauzatutakoa da bakarrenetakoa. Ikerlari horiek egindako azterlanaren arabera, neskek mutilek baino inplikazio-maila nabarmen handiagoa izan ohi dute ikastetxean. Emaitzak sexuaren arabera ezberdinak izatea erraz azal daiteke eskola-inplikazioak motibazioarekin eta izaerarekin lotura zuzena duela onartuz gero. Horrela, dimentsio anitzeko ikuspegitik, Wang eta bere kideen (2011) ikerketak berretsi egiten du nesken inplikazio konduktuala eta emozionala handiagoa dela mutilena baino.

Beste ikerketa batzuen arabera, mutilek ikasteko motibazio txikiagoa dute eta denbora laburragoa eskaintzen diete ikasketekin zerikusia duten egitekoei, eta ondorioz, etorkizun akademiko kaxkarragoa izaten dute (GilFlores, Padilla-Carmona, eta Suárez-Ortega, 2011). Neskek, beren aldetik, hobeto planifikatu ohi dituzte eta denbora gehiago eskaintzen diete ikasketekin lotutako eginkizunei (Kenney-Benson, Pomerantz, Ryan, eta Patrick, 2006). Eskolako kide sentitzeari eta eskolarekiko asebetetze sentimenduei dagokienez ere ezberdintasunak antzeman dira (Furrer eta Skinner, 2003), neskek asebetetze sentimendu handiagoa izaten baitute (Smith, Ito, Gruenewald, eta Yeh, 2010). Horrez gain, mutilek ikasketa-estrategia gutxiago baliatzen dituztela baieztatu izan da, eta porrot akademikoa gertatzen denean, neskek errazago edo neurri handiagoan onartzen dutela beren erantzukizuna (Ghazvini eta Khajehpoura, 2011).

\subsection{Eskola-inplikazioa eta ikasketa-maila}

Orain arte egindako ikerketen arabera, ikasleak ikastetxean duen inplikazioa aldatuz doa ikasketa-mailetan aurrera egin ahala (Finn, 1989; Marks, 2000). Eskola-inplikazioaren inguruko ikerketaren abiapuntua eskola porrota aztertzea izan denez gero (Finn, 1989), nerabezaroan (Mahatmya, Lohman, Matjasko, eta Farb, 2012) eta Bigarren Hezkuntzan (Janosz, Archambauld, Morizot, eta Pagani, 2008; Wylie eta Hodgen, 2012) ikasleek izaten dituzten inplikazio-ereduak aztertzen dituzten ikerlan anitz daude.

Ikerketa ugarik agerian utzi dute eskola-inplikazioa murriztu egiten dela urteek aurrera egin ahala (Liu eta Lu, 2011; Wylie eta Hodgen, 2011), eta bereziki nerabezaroan (Simons-Morton eta Crump, 2003; Wang eta Eccles, 2012). Horrez gainera, hezkuntza-maila batetik besterako trantsiziouneetan ere eskola-inplikazioa txikiagoa izan ohi dela egiaztatu ahal izan da (Liu eta Lu, 2011; Wylie eta Hodgen, 2012). Ikerlarien arabera, ibilbide akademikoan aurrera egin ahala eskolarekiko konpromisoa murriztearen arrazoia nerabeek Bigarren Hezkuntzan dauden bitartean testuinguru sozia- 
lean bizi dituzten aldaketak dira (Li, Lynch, Kalvin, Liu, eta Lerner, 2011; Reschly eta Christenson, 2006).

Ikasleen inplikazio-mailan eragina duten testuinguru-aldaketen artean, honakoak nabarmentzen dituzte adituek: Bigarren Hezkuntzako ikastetxeen tamaina handiagoa, irakasle eta ikasleen arteko hartu-eman urriagoa eta irakasleek, ikaskideek eta gurasoek emandako babesean izaten diren aldaketak (Wang eta Holcombe, 2010). Halaber, barne-motibazioa eta eskola-inplikazioa murrizten dute Bigarren Hezkuntzan lehiakortasuna handitzeak eta emaitza akademikoei garrantzi handiagoa emateak (Gottfried, Fleming, eta Gottfried, 2001), ikasle bakoitzaren ezaugarri pertsonalekin batera (Liu eta Lu, 2011; Wylie eta Hodgen, 2012).

Hala eta guztiz ere, badira motibazioa eta eskola-inplikazioa murrizten ez dela baieztatzen duten ikerketak ere, bereziki nerabezaroari buruzkoak. Janosz-ek eta bere kideek (2008), esaterako, egiaztatu zuten nerabezaroaren hasieraren gertatzen den Bigarren Hezkuntzarako trantsizioaren ostean, ikasleen parte-hartzeak egonkortzeko joera izaten duela nerabezaroan. Baieztapen horren harira, argudiatu izan da nerabezaroan eskolarekin kognitiboki konprometitzeko ahalmena handiagoa dela haurtzaroan baino, aro horretan zenbait trebetasun kognitibo (nork bere buruaz hausnartzeko gaitasuna, pentsamendu estrategikoa, hainbat hipotesi aldi berean kontuan hartzeko ahalmena) azkar garatzearen ondorioz (Mahatmya et al., 2012).

\section{ESKOLA-INPLIKAZIOA, TESTUINGURU-ALDAGAIAK ETA ALDAGAI PSIKOLOGIKOAK}

Eskola-inplikazio kontzeptua funtsezko faktoretzat jotzen da eskolaporrota eragozteko (Voelk, 2012) eta, era berean, doitze psikosoziala ahalbidetzen du (Ros et al., 2012). Hori dela eta, hainbat ikerketa egin dira eskola-inplikazioa erraztu edo iragartzen duten ikasleen ezaugarri indibidualak nahiz testuingurukoak hautemateko.

\subsection{Eskola-inplikazioa eta testuinguru-aldagaiak}

Ikasleen egokitzapenean eskola-inplikazioak duen garrantzia kontuan hartuta, funtsezkoa da aztertzea testuinguruko zein faktorek duen eragina aldagai horretan. Jakin badakigu prozesu proximalek (mikrosistemak), pertsonen arteko harremanek nahiz gizarte-babesak nerabeek nahi dituzten emaitzak lortzeko gaitasuna sustatu edo oztopa dezaketela (Bowen, Rose, Powers, eta Glennie, 2008). Oro har, ikerketa gehienen arabera, gizarte-babes positiboak eskolan parte-hartzea sustatzen du, baina oso ikerlan gutxik 
aztertu dituzte gizarte-babes iturriak eta eskola-inplikazioaren dimentsioekin duten lotura (Wang eta Eccles, 2012).

Sistemen teoria ekologikoaren ikuspegitik, hiru dira eskola-inplikazioarekin lotutako testuinguru nagusiak: familia, berdinak eta eskola (Lam et al., 2012; Ou, 2005; Sinclair, Christenson, Lehr, eta Reschly-Anderson, 2003). Familia inguruneari dagokionez, gurasoek asko babesten edo laguntzen dituztela sentitzen duten nerabeek eskolan emaitza onak lortzeko aukera handiagoa dute (Eccles, Wigfield, eta Schiefele, 1998; Simons-Morton eta Chen, 2009; Wolley eta Bowen, 2007). Ildo horretatik, familia-harremanen kalitateak eskola-inplikazioarekin zerikusia duela frogatu da (Veiga et al., 2012), eta familiaren babesa eta laguntza dutela hautematen duten nerabeek joera handiagoa dutela ekintza prosozialetan parte hartzeko, eskolarekiko interesa agertzeko eta bertan aktiboki parte hartzeko; gainera, jokabide problematiko gutxiago izan ohi dituzte ikastetxean (Wang, Dishion, Stormshak, eta Willett, 2011).

Bestalde, berdinen babesak eta onarpenak nerabeek eskolarekin lotutako asebetetze-sentimendua izatea sustatzen dute (Wang eta Eccles, 2012), eta arlo akademikoarekin nahiz eskola-ekintzekin lotutako emozio positiboak izatea (Juvonen, Espinoza, eta Knifsend, 2012). Are gehiago, eskolako kideekin harreman positiboak dituzten ikasleek eskolarenganako konpromiso konduktual nahiz emozional handiagoa agertu ohi dute (García- Reid, 2007). Lam-en eta bere kideen arabera (2012), ikasleek eskolan duten motibazioa, interesa, ongizatea eta erosotasuna besteekin dituzten harremanen araberakoak dira.

Baina kontuan hartzen badugu eskolako giro soziala bertan dauden helduek baldintzatzen dutela batez ere (Woolley, 2006), ohartuko gara irakasleak eta beren jokabideak biziki garrantzitsuak direla. Ikasgelan duten jokaeraren arabera, irakasleek zaintza, errespetua eta estimua transmiti diezaiekete ikasleei, eta giro horrek ikasleek ikastetxean parte hartzea bultza dezake (Wang eta Eccles, 2012). Izan ere, hainbat ikerketaren arabera, irakasle eta ikasleen arteko harremanak lotura du eskola-inplikazioarekin eta lorpen akademikoekin (Hughes, Luo, Kwok, eta Loyd, 2008; Roorda, Koomen, Spilt, eta Oort, 2011). Halaber, egiaztatu da ikasleek irakasleen babesa eta laguntza dutela sentitzeak eragina duela hainbat inplikazio-adierazle konduktual, emozional eta kognitibotan: eskolan parte-hartzea, eskolarenganako identifikazio-sentimendua eta autoerregulaziorako estrategien erabilera (Wang eta Holcombe, 2010).

\subsection{Eskola-inplikazioa eta aldagai psikologikoak}

Eskola-inplikazioan eragina izan dezaketen ezberdintasun indibidualen ikerketak hezitzaileen eta ikerlarien arreta merezi du; izan ere, eskola- 
doitzearen adierazle hau oso garrantzitsua da eskola-errendimendu baxuari eta inplikazio faltari aurka egiteko. Atal honetan ikasleen inplikazioaren eta hainbat aldagai pertsonalen (autokontzeptua, erresilientzia) arteko harremana aztertu duten ikerlan garrantzitsuenen laburpena egiten da.

\section{Eskola-inplikazioa eta autokontzeptua}

Autokontzeptua pertsona batek, balorazio pertsonaletik eta berarentzat garrantzitsuak diren pertsonen iritzietatik abiatuta bere buruari buruz dituen pertzepzioen multzoa da (Shavelson, Hubner, eta Stanton, 1976). Biziki kontzeptu garrantzitsua da gizarte-zientzietan, eta sakon ikertua izan den kontzeptua da nerabezaroko doitze pertsonalarekin eta eskoladoitzearekin duen loturagatik (Fuentes, García, Gracia, eta Lila, 2011; Rodríguez-Fernández, Droguett, eta Revuelta, 2012).

Hala ere, oso ikerketa gutxik aztertu dute pertsonek beren buruaz duten pertzepzioaren eta eskola-inplikazioaren arteko lotura (Veiga et al., 2014), nahiz eta, nagusi den ebidentzia enpirikoaren arabera, autokontzeptuak lotura zuzena du hainbat hezkuntza aldagairekin, besteak beste, interesarekin, jarraitutasunarekin eta ikasketen aukeraketarekin (Craven eta Marsh, 2008; Nagengast eta Marsh, 2012), emaitza akademiko positiboekin (Marsh eta Martin, 2011; Singh, Chang, eta Dika, 2010) nahiz ikasleek ikasketa-prozesuan duten inplikazioarekin (Inglés, MartínezMonteagudo, García-Fernández, Valle, eta Castejón, 2014).

Autokontzeptua eta eskola-lorpenak aztertu dituzten zenbait ikerlan ere nabarmendu beharra dago. Ghazvini-k (2011), esaterako, aldagai horien arteko lotura aztertu zuen, eta autokontzeptuak literaturan eta matematiketan lortutako emaitzetan eragina duela baieztatu zuen. Veiga-k (1996), bere aldetik, autokontzeptuaren eta zientzietan nahiz matematiketan lortutako errendimenduaren arteko lotura aurkitu zuen, eta ikasle onenek, oro har, beren buruaz ikuspegi positiboagoa dutela baieztatu zuen.

Oro har, egile gehienek autokontzeptuak eta eskola-errendimenduak elkar eragiten dutela uste dute (Appleton, 2012; Marsh, 1990; Reeve eta Tseng, 2011; Veiga et al., 2012), baina oso ikerlan gutxi egin dira dimentsio anitzeko ikuspegia kontuan hartuta ikasleek beren buruaz duten pertzepzioaren eta eskola-inplikazioaren alderdien arteko harremanari buruz, nahiz eta eskola-inplikazioak autokontzeptuaren eta eskola-lorpenen arteko lotura azal dezakeen (Green et al., 2012).

Autokontzeptua eta eskola-inplikazioa aztertzen duten ikerketei dagokienez, nabarmendu beharra dago oraindik ere autokontzeptua orokorrean neurtzen duten lanak egiten direla (Singh et al., 2010), ikerlariek, oro har, autokontzeptua dimentsio anitzeko kontzeptua dela onartzen duten arren eta testuinguruaren arabera dimentsio jakinak ikertzeko beharra dagoela baieztatzen badute ere (Mih eta Mih, 2013). 


\section{Eskola-inplikazioa eta erresilientzia}

Erresilientzia, zailtasunak zailtasun eta arriskuak arrisku, garapen-aldi jakin bati dagozkion garapen-egitekoei era egokian aurre egiteko gaitasuna da (Masten, 2014). Kontzeptuak gero eta garrantzi handiagoa du hezkuntzaren psikologian, eskolan ongizatea sustatzerako orduan duen garrantziagatik (Toland eta Carrigan, 2011), baina oso ikerlan gutxik aztertu dute erresilientziaren eta eskola-inplikazioaren arteko lotura (Jones eta Lafreniere, 2014; Ungar eta Liebengerg, 2013).

Hala eta guztiz ere, psikologia positiboaren eraginez, erresilientzia eta hezkuntzako beste hainbat faktore eta aldagai aztertzen dituzten ikerketak egin dira. Faktore horien artean, esaterako, honakoak aztertu dira: ikasgelako motibazio-giroa (Alonso-Tapia, Nieto, eta Ruiz, 2013), motibatzeko eta emozioak erregulatzeko estrategien erabilera (Fried eta Chapman, 2012) edota gizarte-kalteberatasun testuinguruetan dauden ikasleen errendimendua (Villalta, 2011).

Erresilientzia norbanakoaren ezaugarria dela eta eskola-testuingurura egokitzearekin lotura duela baieztatzen duten ikerlanen artean, Sharkey, You eta Schnoebelen-ena (2008) aipatu beharra dago. Ikerlari horien arabera, erresilientzia eskola-baliabideen eta eskola-inplikazioaren arteko bitartekaria da. Beste ikerlari batzuek erresilientziarekin lotutako alderdiak hobetzeko egindako eskola-ahaleginak eskola-inplikazioa bultza dezakeela iradoki izan dute (Ungar eta Liebenberg, 2013). Eta berriki argitaratutako lanean, Jones-ek eta Lafreniere-k (2014) erresilientziaren eta eskola-inplikazioaren arteko harremana nabarmena dela baieztatzen dute. Amaitzeko, beste ikerketa-ildo batzuetan, erresilientzia eskola-inplikazioaren emaitza den aldagaitzat jotzen da (Irvin, 2012; Malindi eta Machenjedze, 2012).

\section{ONDORIOAK}

Ebidentzia enpirikoak agerian utzi du eskola-inplikazioa funtsezko babesfaktorea dela, hezkuntza- eta gizarte-emaitza positiboak lortzea ahalbidetzen duela eta gazteen garapen moldagarriarekin lotura duela (Li eta Lerner, 2011). Baina hainbat eboluzio-mugarrirekin izan dezakeen loturaz gain, badira aldagai hau ikertzeko bestelako arrazoiak; esate baterako, esku-hartze goiztiarrerako alorra izan daitekeela uste da, eskola-lorpenak ahalbidetu eta balizko eskola-porrotak saihesteko (Fredricks et al., 2004). Helduaroan arrakasta lortzeko ere funtsezkoa izan daitekeela argudiatu izan da; besteak beste, eragina izan lezake goi-mailako ikasketak amaitzean, lan-aukera hobeak lortzean eta autopertzepzio positiboak nahiz ongizatesentimendua izatean (Abbott-Chapman et al., 2014; Li eta Lerner, 2011; Salmela-Aro eta Upadyaya, 2012; Wang eta Peck, 2013). Horrenbestez, azken urteotan eskola-inplikazio kontzeptuarekiko interesa piztu da, oina- 
rri teorikotzat jo baita ikasleen emaitza positiboak hobetzen dituzten prozesuak ulertzen laguntzeko. Azken hamar urteotan kontzeptua azkar garatu da, hainbat alderdi sakon ikertu baitira: inplikazioaren aldagai-kopurua, kontzeptuaren definizioa, ezaugarri psikometriko onargarriak dituzten tresnen bidezko ebaluazioa edota motibazioaren eta inplikazioaren arteko ezberdintasunak. Dena den, ezinbestekoa da ikertzen jarraitzea.

Izan ere, ikastetxeen garapen positiboa eta ahalmena sustatzen dituzten faktoreenganako interesa gero eta handiagoa da, ikasleen eskola-doitzea ahalbidetzen dutelakoan, eta interes horrek eragina izan du hezkuntzaren psikologiaren alorreko ikerketan. Ondorioz, gaur egun, eskola-inplikazioa ez da ikasleen berezko ezaugarritzat jotzen, baizik eta egoera psikologiko aldagarritzat, zeinetan eskola-testuinguruak, familiak eta berdinek eragin nabarmena duten (Reschly eta Christenson, 2006). Halaber, ikerlan ugarik faktore pertsonalek eta testuingurukoek eskola-inplikazioarekin lotura dutela baieztatzen dute (Veiga et al., 2014). Beste era batera esanda, alderdi indibidualak nahiz testuinguruarekin lotutakoak garrantzizkoak dira eskola-inplikazioaren garapenean.

Ikuspegi ekologikotik, eskola-doitzearen adierazle hau beste aldagai batzuekin batera ikertu izan da, lortu nahi diren emaitza akademikoen ondorio nahiz elementu iragarle izan daitekeelakoan (Appleton, 2012; Fredricks et al., 2004; Reeve eta Tseng, 2011). Are gehiago, eskola-inplikazioa autokontzeptua eta eskola-lorpena bezalako aldagai psikologikoen arteko bitartekari izan daitekeela baieztatu izan da (Green et al., 2012). Dena dela, ikerlari eta hezitzaileek testuinguruaren eta ikasleen ezaugarri pertsonalen garrantzia nabarmendu dute; horregatik, oraindik ere ikergai da zenbait aldagaik eskola-inplikazioan izan dezaketen eragin zuzena.

Laburbilduz, eskola-inplikazioa ikerkuntza-ildo garrantzitsua da, uste baita ikasleen garapen positiboa erdiesteko eta eskola-inplikazio falta nahiz eskola-uztea eragozteko garrantzi handikoa izan daitekeela. Kontzeptuak berak ikerketa-ildo berriak jar ditzake abian, eta eskolaren funtzionamendu positiboa hobeto ezagutzen lagun dezake, ikerketa-ildo klasikoa baztertuz gero, zeina defizitean eta ikasleen eskola-egokitzapenean negatiboki eragiten duten alderdien azterketan ardazten da. Horregatik guztiagatik, eskola-inplikazioa hezkuntza-testuinguruan oso baliagarria izan daitekeela uste da, egokitzapen sozialaren adierazlea baita, nahiz eta oraindik ere sakonago ikertu beharra dagoen. Izan ere, orain arte ez da lortu kontzeptuaren definizioa eta metodologia behar beste zehaztea, eskola-inplikazioa kontzeptu sortuberriaren eta ikasgeletan nahiz eskola-programetan esku-hartzeko izan dezakeen erabileraren ezagutzan sakontzeko (Christenson et al., 2012).

Horrenbestez, argi dago eskola-inplikazioa ikerkuntza-arlo emankorra eta garrantzitsua dela, eta lortzen ari diren emaitzak iradokitzaileak direla oso, nahiz eta oraindik era alor ugari ikertzeke dauden. Horiek horrela, eskola-inplikazioaren inguruan oraindik ere luze aztertu beharreko alder- 
diak honakoak dira: kontzeptuaren definizioa bera, eskola-inplikazioaren garapenean eragina duten elementuak, eta psikologiaren nahiz hezkuntzaren alorrean esku hartuz eskola-testuinguruarenganako egokitzapen falta eragotzi edo ikasleen garapena psikosoziala sustatu daitekeen.

\begin{abstract}
The study of school engagement is currently an interesting line of research in the field of educational psychology. This study reviews the scientific literature regarding the conceptualization and measure of school engagement. In addition, the variability of school engagement by gender and age / educational level as well as its relationship with contextual variables (perceived social support from family, friends and teachers) and psychological variables (self-concept and resilience) is analyzed. Although the conceptualization of the construct varies in the studies reviewed, there is a general consensus about the multifaceted nature, which includes three dimensions contained in most of the measuring instruments: behavioral, emotional and cognitive. It is found that the predominant empirical evidence shows that the variables analyzed in this study have a direct association with various indicators of school adjustment, being evident the incipient rise of studies that include school engagement. Finally, the conclusions are developed in the context of positive psychology and outstanding issues for future research are discussed.
\end{abstract}

Keywords: school engagement, theoretical review, contextual variables, psychological variables, secondary education.

El estudio de la implicación escolar (school engagement) constituye en la actualidad una línea de investigación de gran interés en el ámbito de la psicología de la educación. En este trabajo se realiza una revisión teórica actualizada de las principales contribuciones que la literatura científica ofrece sobre la conceptualización y la medida de la implicación escolar. Además, se analiza la variabilidad de la implicación escolar en función del sexo y la edad/nivel educativo, así como su relación con variables contextuales (apoyo social percibido de la familia, amistades y profesorado) y psicológicas (autoconcepto y resiliencia). Aunque la conceptualización del constructo varía en los trabajos revisados, hay consenso general respecto a su naturaleza multifacética, que incluye tres dimensiones recogidas en la mayor 
parte de los instrumentos de medida: conductual, emocional y cognitiva. Se comprueba que la evidencia empírica predominante muestra que las variables analizadas en este estudio guardan una asociación directa con diversos indicadores de ajuste escolar, siendo constatable el incipiente aumento de estudios que incluyen la implicación escolar. Por último, se elaboran las conclusiones en el marco de la psicología positiva y se exponen las cuestiones pendientes más relevantes para futuras investigaciones.

Palabras clave: implicación escolar, revisión teórica, variables contextuales, variables psicológicas, educación secundaria.

L'étude de l'engagement scolaire (school engagement) représente à l'heure actuelle un axe de recherche d'un grand intérêt dans le cadre de la psychologie de l'éducation. Cette étude porte sur un examen théorique à jour des principales contributions de la littérature scientifique à la conceptualisation et à la mesure de l'engagement scolaire. En outre, on y analyse la variabilité de l'engagement scolaire en fonction du sexe et de l'âge / niveau d'éducation, ainsi que son lien avec les variables contextuelles (aide sociale perçue par la famille, amis et professeurs) et psychologiques (concept de soi et résilience). Bien que la conceptualisation du principe d'engagement varie dans les différents projets examinés, il se dégage un consensus général en ce qui concerne sa nature à multiples facettes (ou multidimensionnelle), avec trois dimensions retenues dans la plupart des instruments de mesure : les dimensions comportementale, émotionnelle et cognitive. Les données empiriques prédominantes révèlent que les variables analysées dans cette étude maintiennent un lien direct avec différents indicateurs d'ajustement scolaire, tout en démontrant l'augmentation récente des études portant sur l'engagement scolaire. Enfin, les es conclusions de cette étude sont élaborées dans le cadre de la psychologie positive et on expose également les questions en suspens les plus significatives pour les recherches futures.

Mots-clé: engagement scolaire, examen théorique, variables contextuelles, variables psychologiques, enseignement secondaire.

\section{ERREFERENTZIAK}

Abbott-Chapman, J., Martin, K., Ollington, N., Venn, A., Dwyer, T., eta Gall, S. (2014). The longitudinal association of childhood school engagement with adult educational and occupational achievement: Findings from an Australian national study. British Educational Research Journal, 40(1), 102-120. doi:10.1002/berj.3031 
Alonso-Tapia, J., Nieto, C., eta Ruíz, M. A. (2013). Measuring subjective resilience despite adversity due to family, peers and teachers. The Spanish Journal of Psychology, 16, 1-13. doi:10.1017/sjp.2013.33

Appleton, J. J. (2012). Systems consultation: Developing the assessment-to-intervention link with the Student Engagement Instrument. In S. L. Christenson, A. L. Reschly, C. Wylie, S. L. Christenson, A. L. Reschly eta C. Wylie (Zuz.), Handbook of research on student engagement (725-741 orr.). New York, NY, US: Springer Science + Business Media. doi:10.1007/978-1-4614-2018-7_35

Appleton, J. J., Christenson, S. L., eta Furlong, M. J. (2008). Student engagement with school: Critical conceptual and methodological issues of the construct. Psychology in the Schools, 45(5), 369-386. doi:10.1002/pits.20303

Appleton, J. J., Christenson, S. L., Kim, D., eta Reschly, A. L. (2006). Measuring cognitive and psychological engagement: Validation of the Student Engagement Instrument. Journal of School Psychology, 44(5), 427-445. doi:10.1016/j.jsp.2006.04.002

Betts, J. E., Appleton, J. J., Reschly, A. L., Christenson, S. L., eta Huebner, E. S. (2010). A study of the factorial invariance of the Student Engagement Instrument (SEI): Results from middle and high school students. School Psychology Quarterly, 25(2), 84-93. doi:10.1037/a0020259

Blumenfeld, P., Modell, J., Bartko, W., Secada, W. G., Fredricks, J. A., Friedel, J., eta Paris, A. (2005). School engagement of inner-city students during middle childhood. In C. R. Cooper, C. Coll, W. Bartko, H. Davis eta C. Chatman (Zuz.), Developmental pathways through middle childhood: Rethinking contexts and diversity as resources (145-170 orr.). Mahwah, NJ US: Lawrence Erlbaum Associates Publishers.

Bowen, G. L., Rose, R. A., Powers, J. D., eta Glennie, E. J. (2008). The joint effects of neighborhoods, schools, peers, and families on changes in the school success of middle school students. Family Relations: An Interdisciplinary Journal of Applied Family Studies, 57(4), 504-516. doi:10.1111/j.17413729.2008.00518.x

Burden, R., eta Burdett, J. (2005). Factors associated with successful learning in pupils with dyslexia: a motivational analysis. British Journal of Special Education, 32(2), 100-104. doi: 10.1111/j.0952-3383.2005.00378.x

Christenson, S. L., Reschly, A. L., eta Wylie, C. (2012). Handbook of research on student engagement. New York, NY US: Springer Science + Business Media. doi:10.1007/978-1- 4614-2018-7

Connell, J. P., eta Wellborn, J. G. (1991). Competence, autonomy, and relatedness: A motivational analysis of self-system processes. In M. R. Gunnar eta L. Sroufe (Zuz.), Self processes and development (43-77 orr.). Hillsdale, NJ England: Lawrence Erlbaum Associates, Inc.

Craven, R. G., eta Marsh, H. W. (2008). The centrality of the self-concept construct for psychological wellbeing and unlocking human potential: Implications for child and educational psychologists. Educational and Child Psychology, 25(2), 104-18.

Eccles, J. S., Wigfield, A., eta Schiefele, U. (1998). Motivation to succeed. In N. Eisenberg eta N. Eisenberg (Zuz.), Handbook of child psychology: Social, emotional, and personality development (1017-1095 orr.). Hoboken, NJ, US: John Wiley \& Sons Inc. 
Finn, J. D. (1989). Withdrawing from school. Review of Educational Research, 59(2), 117-142. doi:10.2307/1170412

Finn, J. D., eta Zimmer, K. S. (2012). Student engagement: What is it? Why does it matter?. In S. L. Christenson, A. L. Reschly eta C. Wylie (Zuz.), Handbook of research on student engagement (97-131 orr.). New York, NY US: Springer Science + Business Media. doi:10.1007/978-1-4614-2018-7_5

Fredricks, J. A., Blumenfeld, P. C., Friedel, J., eta Paris, A. (2005). School engagement. In K. A. Moore y L. Lippman (Zuz.), Conceptualizing and measuring indicators of positive development: What do children need to flourish (305-321 orr.). New York: Kluwer Academic/Plenum Press.

Fredricks, J. A., Blumenfeld, P. C., eta Paris, A. H. (2004). School engagement: Potential of the concept, state of the evidence. Review of Educational Research, 74(1), 59-109. doi:10.3102/00346543074001059

Fredricks, J. A., eta McColskey, W. (2012). The measurement of student engagement: A comparative analysis of various methods and student self-report instruments. In S. L. Christenson, A. L. Reschly, C. Wylie, S. L. Christenson, A. L. Reschly eta C. Wylie (Zuz.), Handbook of research on student engagement (763-782 orr.). New York, NY, US: Springer Science + Business Media. doi:10.1007/978-1-4614-2018-7_37

Fried, L., eta Chapman, E. (2012). An investigation into the capacity of student motivation and emotion regulation strategies to predict engagement and resilience in the middle school classroom. The Australian Educational Researcher, 39(3), 295-311. doi: 10.1007/s13384-011-0049-1.

Fuentes, M. C., García, J., Gracia, E., eta Lila, M. (2011). Autoconcepto y ajuste psicosocial en la adolescencia. Psicothema, 23(1), 7-12.

Furlong, M. J., eta Christenson, S. L. (2008). Engaging students at school and with learning: A relevant construct for all students. Psychology in the Schools, 45(5), 365-368. doi:10.1002/pits.20302

Furlong, M. J., Whipple, A. D., Jean, G. S., Simental, J., Soliz, A., eta Punthuna, S. (2003). Multiple contexts of school engagement: Moving toward a unifying framework for educational research and practice. California School Psychologist, 8(1), 99-113. doi:10.1007/BF03340899

Furrer, C., eta Skinner, E. (2003). Sense of relatedness as a factor in children's academic engagement and performance. Journal of Educational Psychology, 95(1), 148-162. doi:10.1037/0022-0663.95.1.148

Garcia-Reid, P. (2007). Examining social capital as a mechanism for improving school engagement among low income Hispanic girls. Youth and Society, 39(2), 164-181. doi:10.1177/0044118X07303263

Ghazvini, S. D. (2011). Relationships between academic self-concept and academic performance in high school students. Procedia-Social and Behavioral Sciences, 15, 1034-1039.

Gil-Flores, J., Padilla-Carmona, M. T., eta Suárez-Ortega, M. (2011). Influence of gender, educational attainment and family environment on the educational aspirations of secondary school students. Educational Review, 63(3), 345-363. d oi:10.1080/00131911.2011.571763

Glanville, J. L., eta Wildhagen, T. (2007). The measurement of school engagement: Assessing dimensionality and measurement invariance across race and 
ethnicity. Educational and Psychological Measurement, 67(6), 1019-1041. doi:10.1177/0013164406299126

González, M. T. (2010). El alumno ante la escuela y su propio aprendizaje: Algunas líneas de investigación en torno al concepto de implicación. REICE: Revista Electrónica Iberoamericana sobre Calidad, Eficacia y Cambio en Educación, 8(4), 10-31.

Gottfried, A. E., Fleming, J. S., eta Gottfried, A. W. (2001). Continuity of academic intrinsic motivation from childhood through late adolescence: A longitudinal study. Journal of Educational Psychology, 93(1), 3-13. doi:10.1037/0022-0663.93.1.3

Green, J., Liem, G. D., Martin, A. J., Colmar, S., Marsh, H. W., eta McInerney, D. (2012). Academic motivation, self-concept, engagement, and performance in high school: Key processes from a longitudinal perspective. Journal of Adolescence, 35(5), 1111-1122. doi:10.1016/j.adolescence.2012.02.016

Hughes, J. N., Luo, W., Kwok, O. M., eta Loyd, L. K. (2008). Teacher-student support, effortful engagement, and achievement: A 3-year longitudinal study. Journal of Educational Psychology, 100(1), 11-14. doi:10.1037/0022-0663.100.1.1

Inglés, C., Martínez-Monteagudo, M., García-Fernández, J., Valle, A., eta Castejón, J. (2014). Perfiles de orientaciones de metas y autoconcepto de estudiantes de Educación Secundaria. Revista de Psicodidáctica, 20(1). doi:10.1387/ RevPsicodidact.1023

Irvin, M. J. (2012). Role of student engagement in the resilience of African American adolescents from low-income rural communities. Psychology in the Schools, 49(2), 176-193. doi:10.1002/pits.20626

Janosz, M., Archambault, I., Morizot, J., eta Pagani, L. S. (2008). School engagement trajectories and their differential predictive relations to dropout. Journal of Social Issues, 64(1), 21-40. doi:10.1111/j.1540-4560.2008.00546.x

Jimerson, S. R., Campos, E., eta Greif, J. L. (2003). Toward an understanding of definitions and measures of school engagement and related terms. California School Psychologist, 87-27. doi:10.1007/BF03340893

Jones, G., eta Lafreniere, K. (2014). Exploring the role of school engagement in predicting resilience among bahamian youth. Journal of Black Psychology, 40(1), 47-68. doi: 10.1177/0095798412469230

Juvonen, J., Espinoza, G., eta Knifsend, C. (2012). The role of peer relationships in student academic and extracurricular engagement. In S. L. Christenson, A. L. Reschly, C. Wylie, S. L. Christenson, A. L. Reschly eta C. Wylie (Zuz.), Handbook of research on student engagement (387-401 orr.). New York, NY, US: Springer Science + Business Media. doi:10.1007/978-1-4614-2018-7_18

Kenney-Benson, G. A., Pomerantz, E. M., Ryan, A. M., eta Patrick, H. (2006). Sex differences in math performance: The role of children's approach to schoolwork. Developmental Psychology, 42(1), 11-26. doi:10.1037/0012-1649.42.1.11

Kristjánsson, K. (2012). Positive psychology and positive education: Old wine in new bottles?. Educational Psychologist, 47(2), 86-105. doi: 10.10080/00461520.2011.610678

Lam, S., Wong, B. H., Yang, H., eta Liu, Y. (2012). Understanding student engagement with a contextual model. In S. L. Christenson, A. L. Reschly eta C. 
Wylie (Zuz.), Handbook of research on student engagement (403-419 orr.). New York, NY US: Springer Science + Business Media. doi:10.1007/978-1-4 614-2018-7_19

Lewis, A. D., Huebner, E. S., Malone, P. S., eta Valois, R. F. (2011). Life satisfaction and student engagement in adolescents. Journal of Youth and Adolescence, 40(3), 249-262. doi:10.1007/s10964-010-9517-6

Li, Y., eta Lerner, R. M. (2011). Trajectories of school engagement during adolescence: Implications for grades, depression, delinquency, and substance use. Developmental Psychology, 47(1), 233-247. doi:10.1037/ a0021307

Li, Y., eta Lerner, R. M. (2013). Interrelations of behavioral, emotional, and cognitive school engagement in high school students. Journal of Youth and Adolescence, 42(1), 20-32. doi:10.1007/s10964-012-9857-5

Li, Y., Lynch, A. D., Kalvin, C., Liu, J., eta Lerner, R. M. (2011). Peer relationships as a context for the development of school engagement during early adolescence. International Journal of Behavioral Development, 35(4), 329-342. doi: $10.1177 / 0165025411402578$

Liu, Y., eta Lu, Z. (2011). Trajectories of Chinese students' sense of school belonging and academic achievement over the high school transition period. Learning and Individual Differences, 21(2), 187-190. doi:10.1016/j.lindif.2010.12.007

Mahatmya, D., Lohman, B. J., Matjasko, J. L., eta Farb, A. (2012). Engagement across developmental periods. In S. L. Christenson, A. L. Reschly eta C. Wylie (Zuz.), Handbook of research on student engagement (45-63 orr.). New York, NY US: Springer Science + Business Media. doi:10.1007/978-1-46142018-7_3

Malindi, M., eta Machenjedze, N. (2012). The role of school engagement in strengthening resilience among male street children. South African Journal of Psychology, 42(1), 71-81.

Marks, H. M. (2000). Student engagement in instructional activity: Patterns in the elementary, middle, and high school years. American Educational Research Journal, 37(1), 153-184. doi:10.2307/1163475

Marsh, H. W. (1990). The structure of academic self-concept: The Marsh/ Shavelson model. Journal of Educational Psychology, 82(4), 623-636. doi: $10.1037 / 0022-0663.82 .4 .623$

Marsh, H. W., eta Martin, A. J. (2011). Academic self-concept and academic achievement: Relations and causal ordering. British Journal of Educational Psychology, 81(1), 59-77. doi: 10.1348/000709910X503501

Maslow, A. H., Frager, R., eta Cox, R. (1970). Motivation and personality. J. Fadiman, eta C. McReynolds (Eds.). New York: Harper \& Row.

Masten, A. S. (2014), Global perspectives on resilience in children and youth. Child Development, 85(1), 6-20. doi: 10.1111/cdev.12205

McClelland, D. C. (1985). How motives, skills, and values determine what people do. American Psychologist, 40(7), 812-825. doi:10.1037/0003066X.40.7.812

Mih, V., eta Mih, C. (2013). Perceived autonomy-supportive teaching, academic self-perceptions and engagement in learning: Toward a process model of academic achievement. Cognitive, Creier, Comportament/Cognition, Brain, Behavior, 17(4), 289-313. 
Motti-Stefanidi, F., eta Masten, A. S. (2013). School success and school engagement of immigrant children and adolescents: A risk and resilience developmental perspective. European Psychologist, 18(2), 126-135. doi:10.1027/1016-9040/a000139

Nagengast, B., eta Marsh, H. W. (2012). Big fish in little ponds aspire more: Mediation and cross- cultural generalizability of school-average ability effects on self-concept and career aspirations in science. Journal of Educational Psychology, 104(4), 1033. doi: 10.1177/0022022113519858

Newmann, F. (1981). Reducing student alienation in high schools: Implications of theory. Harvard Educational Review, 51(4), 546-564.

$\mathrm{Ou}, \mathrm{S}$. (2005). Pathways of long-term effects of an early intervention program on educational attainment: Findings from the Chicago longitudinal study. Journal of Applied Developmental Psychology, 26(5), 578-611. doi:10.1016/j.appdev.2005.06.008

Perdue, N. H., Manzeske, D. P., eta Estell, D. B. (2009). Early predictors of school engagement: Exploring the role of peer relationships. Psychology in the Schools, 46(10), 1084-1097. doi:10.1002/pits.20446

Reeve, J. (2012). A self-determination theory perspective on student engagement. In S. L. Christenson, A. L. Reschly, C. Wylie, S. L. Christenson, A. L. Reschly eta C. Wylie (Zuz.), Handbook of research on student engagement (149-172 orr.). New York, NY, US: Springer Science + Business Media. doi:10.1007/978-1-4614-2018-7_7

Reeve, J., eta Tseng, C. (2011). Agency as a fourth aspect of students' engagement during learning activities. Contemporary Educational Psychology, 36(4), 257-267. doi:10.1016/j.cedpsych.2011.05.002

Reschly, A. L., eta Christenson, S. L. (2006). Prediction of dropout among students with mild disabilities: A case for the inclusion of student engagement variables. Remedial and Special Education, 27(5), 276-292. doi:10.1177/0741 9325060270050301

Rodríguez-Fernández, A., Droguett, L., eta Revuelta, L. (2012). Ajuste escolar y personal en la adolescencia: El papel del autoconcepto académico y del apoyo social percibido. Revista de Psicodidáctica, 17(2). doi: 0.1387/Rev.Psicodidact.3002

Roorda, D. L., Koomen, H. M., Spilt, J. L., eta Oort, F. J. (2011). The influence of affective teacher-student relationships on students' school engagement and achievement a meta- analytic approach. Review of Educational Research, 81(4), 493-529. doi: 10.3102/0034654311421793

Ros, I. (2009). La implicación del estudiante con la escuela. Revista de Psicodidáctica, 14(1), 79-92

Ros, I., (2014). El sentimiento de pertenencia de los estudiantes por curso y género en una cooperativa escolar de trabajo asociado. Revista de Psicología y Educación, 9(1), 201-218.

Ros, I., Goikoetxea, J., Gairín, J., eta Lekue, P. (2012). Implicación del alumnado en la escuela: Diferencias interindividuales e intercentros. Revista de Psicodidáctica, 17(2), 291-307. doi: 10.1387/Rev.Psicodidact.4496

Russell, V. J., Ainley, M., eta Frydenberg, E. (2005). Student motivation and engagement. Schooling Issues Digest. Australian Government, Department of Education, Science and Training. 
Salmela-Aro, K., eta Upadyaya, K. (2012). The schoolwork engagement inventory: Energy, dedication, and absorption (EDA). European Journal of Psychological Assessment, 28, 60-67. doi:10.1027/1015-5759/a000091

Sharkey, J. D., You, S., eta Schnoebelen, K. (2008). Relations among school assets, individual resilience, and student engagement for youth grouped by level of family functioning. Psychology in the Schools, 45(5), 402-418. doi:10.1002/pits.20305

Shavelson, R. J., Hubner, J. J., eta Stanton, G. C. (1976). Self-concept: Validation of construct interpretations. Review of Educational Research, 46(3), 407-441. doi: $10.2307 / 1170010$

Simons-Morton, B., eta Chen, R. (2009). Peer and parent influences on school engagement among early adolescents. Youth \& Society, 41(1), 3-25. doi:10.1177/0044118X09334861

Simons-Morton, B. G., eta Crump, A. D. (2003). Association of parental involvement and social competence with school adjustment and engagement among sixth graders. Journal of School Health, 73(3), 121-126. doi: $10.1111 / \mathrm{j} .1746-1561.2003 . t b 03586 . x$

Sinclair, M. F., Christenson, S. L., Lehr, C. A., eta Anderson, A. R. (2003). Facilitating student engagement: Lessons learned from Check \& Connect longitudinal studies. The California School Psychologist, 8(1), 29-41. doi:10.1007/ BF03340894

Singh, K., Chang, M., eta Dika, S. (2010). Ethnicity, self-concept, and school belonging: Effects on school engagement. Educational Research for Policy and Practice, 9(3), 159-175. doi:10.1007/s10671-010-9087-0

Skinner, E. A., Kindermann, T. A., Connell, J. P., eta Wellborn, J. G. (2009). Engagement and disaffection as organizational constructs in the dynamics of motivational development. In K. R. Wentzel eta A. Wigfield (Zuz.), Handbook of motivation at school (223-245 orr.). New York: Routledge/Taylor \& Francis Group.

Smith, D. C., Ito, A., Gruenewald, J., eta Yeh, H. (2010). Promoting school engagement: Attitudes toward school among American and Japanese youth. Journal of School Violence, 9(4), 392-406. doi:10.1080/15388220.2010.509308

Toland, J., eta Carrigan, D. (2011). Educational psychology and resilience: New concept, new opportunities. School Psychology International, 32(1), 95-106. doi: $10.1177 / 0143034310397284$

Ungar, M., eta Liebenberg, L. (2013). Ethnocultural factors, resilience, and school engagement. School Psychology International, 34(5), 514-526. doi: $10.1177 / 0143034312472761$

Veiga F. H. (1996). Autoconceito e rendimento dos jovens em matemática e ciências: Análise por grupos com diferente valorição do sucesso. Revista de Educação, 5, 41-53.

Veiga F. H., Burden, R., Appleton, J., Céu, T., eta Galvao, D. (2014). Student's engagement in school: conceptualization and relations with personal variables and academic performance. Revista de Psicología y Educación, 9(1), 29-47.

Veiga, F. H., Carvalho, C., Almeida, A., Taveira, C., Janeiro, I., Baía, S., ... Caldeira, S. (2012). Students' engagement in schools: differentiation and promotion. In M. F. Patrício, L. Sebastião, J. M. Justo eta J. Bonito (Arg.), $D a$ exclusão à excelência: Caminhos organizacionais para a qualidade da edu- 
cação (117-123 orr.). Montargil: Associação da Educação Pluridimensional e da Escola Cultural.

Villalta, M. A. (2011). Factores de resiliencia asociados al rendimiento académico en estudiantes de contextos de alta vulnerabilidad social. Revista de Pedagogía, 31(88), 159-188.

Voelkl, K. E. (1997). Identification with school. American Journal of Education, 105(3), 294-318. doi:10.1086/444158

Voelkl, K. E. (2012). School identification. In S. L. Christenson, A. L. Reschly y C. Wylie (Zuz.), Handbook of research on student engagement (193-218 orr.). New York: Springer.

Wang, M., Dishion, T. J., Stormshak, E. A., eta Willett, J. B. (2011). Trajectories of family management practices and early adolescent behavioral outcomes. Developmental Psychology, 47(5), 1324-1341. doi:10.1037/a0024026

Wang, M., eta Eccles, J. S. (2012). Social support matters: Longitudinal effects of social support on three dimensions of school engagement from middle to high school. Child Development, 83(3), 877-895. doi:10.1111/j.14678624.2012.01745.x

Wang, M., eta Holcombe, R. (2010). Adolescents' perceptions of school environment, engagement, and academic achievement in middle school. American Educational Research Journal, 47(3), 633-662. doi:10.3102/0002831209361209

Wang, M. T., eta Peck, S. C. (2013). Adolescent educational success and mental health vary across school engagement profiles. Developmental Psychology, 49(7), 1266-1276. doi:10.1037/a0030028

Wang, M., Willett, J. B., eta Eccles, J. S. (2011). The assessment of school engagement: Examining dimensionality and measurement invariance by gender and race/ethnicity. Journal of School Psychology, 49(4), 465-480. doi:10.1016/j.jsp.2011.04.001

Wehlage, G. G., Rutter, R. A., Smith, G. A., Lesko, N., eta Fernandez, R. R. (1989). Reducing the risk: Schools as communities of support. Philadelphia: Falmer Press.

Woolley, M. E. (2006). Advancing a positive school climate for students, families, and staff. In C. Franklin, M. B. Harris eta P. Allen-Meares (Zuz.), The school services sourcebook (777-784 orr.). New York: Oxford University Press.

Woolley, M. E., eta Bowen, G. L. (2007). In the context of risk: Supportive adults and the school engagement of middle school students. Family Relations: An Interdisciplinary Journal of Applied Family Studies, 56(1), 92-104. doi:10.1111/j.1741-3729.2007.00442.x

Wylie, C., eta Hodgen, E. (2012). Trajectories and patterns of student engagement: Evidence from a longitudinal study. In S. L. Christenson, A. L. Reschly, C. Wylie, S. L. Christenson, A. L. Reschly eta C. Wylie (Zuz.), Handbook of research on student engagement (585-599 orr.). New York, NY, US: Springer Science + Business Media. doi:10.1007/978-1-4614-2018-7_28

Yazzie- Mintz, E. (2007). Voices of students on engagement: A report on the 2006 high school survey of student engagement. Bloomington, IN: Center for Evaluation \& Educational Policy, Indiana University.

Zimmer-Gembeck, M. J., Chipuer, H. M., Hanisch, M., Creed, P. A., eta McGregor, L. (2006). Relationships at school and stage-environment fit as resources for adolescent engagement and achievement. Journal of Adolescence, 29(6), 911-933. 